\title{
LA PROTECCIÓN DEL PATRIMONIO HISTÓRICO: SUS PRECEDENTES
}

\author{
por \\ CONCHA FONTENLA SAN JUAN
}

\begin{abstract}
Nuestro siglo se ha caracterizado por un sorpendente desarrollo en lo que a la conservación del patrimonio artístico se refiere, ya desde su albor la obra de arte conquistó definitivamente la categoría de Monumento Histórico-Artístico, su consideración como Bien de Interés Cultural e incluso, en algunos casos, la denominación de Patrimonio de la Humanidad. Es también en este siglo XX cuando los partidos políticos (del más diverso signo) han incluido, dentro de sus programas y presupuestos, importantes capítulos dedicados a la protección, conservación, o —en caso necesario- restauración de su patrimonio histórico.
\end{abstract}

\section{DEL ELECTICISMO ROMÁNICO AL ECLECTICISMO DECIMONÓNICO}

Conviene reflexionar que temas tan presumiblemente actuales como conservación, restauración, rehabilitación, nuevas funciones..., hunden sus más profundas raíces en la cultura ecléctica romana pero que, debido a sucesivos períodos de evolución/regresión histórica, los avances han sido tan lentos que se necesitarían — nada menos - que dieciocho siglos para que, con el advenimiento de la cultura ecléctica decimonónica, se consiga cerrar este ciclo evolutivo.

Entre el eclecticismo romano y el eclecticismo decimonónico, pues, tiene lugar un largo proceso de maduración que culmina con el moderno culto a los monumentos y con la elaboración de toda una serie de teorías cuyo objetivo principal es la protección y transmisión del patrimonio cultural heredado a generaciones venideras.

"CUADERNOS DE ESTUDIOS GALLEGOS", Tomo XLII, Fascículo 107, Santiago 1995. 


\section{CRITERIO SELECTIVO}

A la hora de iniciar el análisis, hay que considerar que cada etapa de la historia de la humanidad ha tenido su peculiar manera de mirar hacia el pasado y que siempre lo ha hecho procediendo a una selección preferencial condicionada por sus propios planteamientos: aceptando o negando, valorando o ignorando los documentos históricos que en forma de edificios, esculturas, pinturas les han transmitido hombres de otras épocas, de otras civilizaciones. De cualquier modo, y pese a los intereses parciales de cada período histórico, estos monumentos-documento, al cabo de los años, han aportado datos de incalculable interés al estudio de la memoria colectiva.

Una obra de arte puede ser ignorada o negada en su propio tiempo para ser rememorada siglos después, o suceder todo lo contrario, llegar a adquirir un valor extraordinario para sus contemporáneos y pasar luego desapercibida o silenciada - incluso premeditadamente - durante generaciones enteras, hasta que - en un momento dado - por acontecimientos en los que tratamos de profundizar, se vea rescatada del olvido, pudiendo entonces llegar a adquirir tal fuerza que sea incluso capaz de modificar la opinión, ya no sólo con respecto a la obra de arte como documento y huella, sino hacia la sociedad que la ha hecho posible.

De ello podemos deducir que una obra de arte se transforma en memoria, si quien la recibe se siente identificado con ella, haciéndola de nuevo vital.

Con esta nueva estima hacia el pasado la sociedad está redefiniendo el presente y como consecuencia, cambiando su posición frente a las obras que dejará al futuro. En la medida en que esta valoración aumenta, surge paulatinamente un creciente interés por conservar los legados de los antepasados y paralelamente, el deseo de transmitirlos, en el mejor estado posible a las generaciones venideras.

Este proceso, así entendido, de hacer pública la idea de conservar y administrar la obra de arte, se consolida en el siglo XIX y se sistematiza a raíz del nacimiento de la conciencia histórica que, amparada en la investigación histórica, se inicia en la lejana y ecléctica cultura romana. 


\section{ROMA}

El eclecticismo es una etapa final, dentro de la evolución de los estilos artísticos, mostrándose como el resultado de un proceso artístico excesivamente intelectualizado. En Roma las diferentes corrientes artísticas, la con-fusión de ideas procedentes tanto de la Grecia Clásica como del Helenismo, fueron utilizadas en el momento de la con-figuración de su estilo. Producto de la expoliación de los numerosos pueblos recientemente conquistados, llegaron a Roma piezas artísticas de muy distinta procedencia; esta sociedad en la que sus manifestaciones artísticas eran todavía muy escasas y no estaban aún consolidadas, «consumió» arte antes de crearlo, asumiendo como propias formas de diversas corrientes estéticas.

En Roma, nos encontramos por primera vez, aunque en estado embrionario y sin evolución posterior, con un incipiente culto a las obras de arte de la antigüedad, aunque esta valoración era en base - exclusivamentede su valor artístico. El valor histórico, su consideración de monumentodocumento, se inicia y se desarrolla - como ya se ha expuesto- en el siglo XIX pero su consolidación definitiva no llegará hasta principios del siglo XX, momento en el que se independizan todos los estilos artísticos, superaron el anterior criterio de valoración selectiva. Aloïs Riegl estudia y sistematiza esta evolución en El culto moderno a los monumentos, proponiéndonos al respecto:

«... Hasta comienzos del siglo XX no se ha llegado a extraer las consecuencias necesarias del pensamiento histórico evolutivo y a exponer con claridad que toda creación artística pasada es algo irrecuperable y que, por tanto, no puede entenderse de ningún modo como una norma.»1

\section{EL COLECCIONISMO}

¿Con qué criterio respondió el hombre de la calle ante toda esta serie de acontecimientos que se precipitaron sobre Roma - en tan sólo unos años-y que cambiaron no sólo su sensibilidad artística, sino su situación

${ }^{1}$ RIEGL, Aloïs. El culto moderno a los monumentos. Visor Distr., S.A., Madrid 1987, pág. 27.

"CUADERNOS DE ESTUDIOS GALLEGOS", Tomo XLII, Fascículo 107, Santiago 1995. 
social y económica?. ¿Qué actitud tomaron los romanos hacia el pasado?. La reacción inmediata de Roma fue el coleccionismo. Los romanos, recientemente enriquecidos, quisieron emular el lujo y la ostentación que habían visto en las cortes helenísticas recientemente conquistadas. De ello tenemos abundantes noticias en la literatura de la época. Petronio, consular de la época de Néron, describe en «El Satiricón» escenas de la vida romana en las que está presente este nuevo gusto por las antigüedades, vistas desde la perspectiva siempre mordaz del autor:

«-Soy el único que posee corintios auténticos — dijo Trimalción a Agamenón que estaba observando con curiosidad la bandeja.

Yo esperaba que —con su acostumbrada locuacidad-dijera Trimalcón que se hacía traer vasos de Corinto. Pero se le ocurrió algo mejor.

- Quizás me preguntas - dijo- por qué soy el único que posee corintios auténticos. Pues, muy simple, porque el bromista al que se los compro se llama Corinto. ¿Acaso no es corinto lo de Corintio?. Y no me toméis por majadero, pues sé muy bien de dónde proceden los auténticos corintios». ${ }^{2}$

¿Por qué se desató una afición tan desmedida hacia la Antigüedad que provocó el agotamiento de piezas tanto helenísticas como griegas, hasta el punto de que este apetito insaciable hubo de nutrirse de «copias» realizadas en los talleres Neoáticos?. La propia mentalidad del pueblo romano nos da la respuesta; la adquisición de obras artísticas estaba estrechamente vinculada con la idea que regía esta sociedad y que condicionaba muchas de las actuaciones de estos hombres: su obsesión por aumento del patrimonio como medio para alcanzar el tan deseado ascenso social. Las obras de arte eran valoradas como «falsas cartas de nobleza» en un mundo en el que el crecimiento económico se había producido de modo muy rápido. Muchos de los ciudadanos romanos se habían visto liberados recientemente de su condición de esclavos, llegando a poseer una inmensa fortuna en poco tiempo. Estos «nuevos ricos» trataron de emular la afición de sus antiguos señores, en búsqueda de su propia autoafirmación.

Muchos de ellos, llegaron a ser coleccionistas tan insaciables y despiadados que en su afán de acumular objetos griegos, expoliaron las

${ }^{2}$ PETRONIUS, Satiricón. Alianza Editorial, S.A. Madrid 1989. (nº 50).

"CUADERNOS DE ESTUdIOS GALLEGOS", Tomo XLII, Fascículo 107, Santiago 1995. 
nuevas provincias romanas, aún después de haberse retirado las tropas. Leyendo los discursos de Cicerón, nos encontramos con un personaje paradigmático: Verres, quien acumuló una ingente cantidad de obras procedentes sobre todo de Asia Menor, hasta llegar a formar una colección inmensa, llegando incluso a poseer un taller en Siracusa para readaptación y reutilización de piezas. Ningún comentario es más explícito que el propio texto:

«Voy a referirme ahora a una pasión de ése, como él la llama; sus amigos, enfermedad y locura; los sicilianos bandidaje...

Declaro que en toda Sicilia, una provincia tan rica, de tanta tradición, con tantas ciudades, con tantas familias tan opulentas, no hubo ningún vaso de plata, de Corinto o de Delos, ninguna joya o perla, ningún objeto de oro o marfil, ninguna estatua de bronce, mármol o marfil, afirma que no hubo ninguna pintura, ni tabla ni en tapiz, que

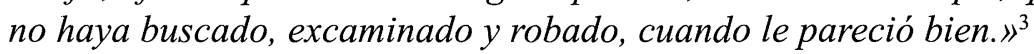

\section{COLECCIONES PÚBLICAS}

Poco antes del inicio de nuestra era, durante el gobierno de Agripa, podemos apreciar un cambio de actitud al respecto, surgiendo las primeras colecciones públicas, con la consecuencia inmediata del declive de las colecciones privadas.

\section{CONSERVACIÓN DE MONUMENTOS}

Por otro lado, y una vez superados los prejuicios impuestos por la mentalidad Republicana, la valoración del pasado no dejó de aumentar y con ella empezaron a surgir incipientes deseos de conservación de sus manifestaciones artísticas. Un ejemplo claro lo descubrimos en Augusto, reconocido como «el restaurador de los sagrados templos y de las obras públicas»; tenemos en él al prototipo de gobernante que utiliza la conservación de los monumentos de épocas pasadas, con fines exclusivamente propa-

${ }^{3}$ TULIO CICERÓN, M. Discursos. Tomo II. Verrinas. Segunda sesión. (Discursos III-V). Editorial Gredos. Madrid 1990, pág. 133.

"CUADERNOS DE ESTUdiOS GALLEGOS", Tomo XLII, Fascículo 107, Santiago 1995. 
gandísticos. Su deseo era llevar a cabo, tras la confusión provocada por las guerras civiles, un proyecto de vuelta a los valores de sobriedad y austeridad típicos de los tiempos republicanos. El poeta Horacio participa, literariamente, en esta restauración política y moral pretendida en este período augústeo que expresa en el contenido de sus Odas:

«Tu, romano, expiarás inmerecidamente los delitos de tus mayores, hasta las hayas reconstruido los templos, las moradas ruinosas de los dioses y sus imágenes ensuciadas por el negro humo.... ${ }^{4}$

Pero, la afición al coleccionismo de obras de arte, no llevó consigo respeto alguno a la civilización que las había hecho posibles, su valoración seguía criterios absolutamente selectivos: el valor intrínseco por las antigüedades no llegaría como ya se ha expuesto, hasta el siglo XIX.

\section{OTROS CASOS AISLADOS}

Podemos citar, el ejemplo de Vespasiano que en el año 75 de nuestra era, restaura el Teatro Marcello de Roma. Adriano, además de su pasión por la civilización griega, traducida en un arte oficial dominada por el clasicismo, lleva también a cabo las labores de reconstrucción y reutilización del Panteón en el año 118.

A lo largo de la Edad Media, podemos encontrar también otros ejemplos aislados de respetuosa conservación de obras de arte antiguas, pero no serán nunca referencias al culto a los monumentos con el concepto actual, sino simplemente culto a las ideas que querían emular. Son, en la mayoría de los casos, intentos imperialistas que trataban de transmitir el poder y la grandeza del antiguo Imperio, al que el hombre medieval consideraba solamente temporalmente interrumpido, pero todavía existente.

De todos ellos destacaremos al ostrogodo Teodorico que después de vagar sin asentamiento territorial fijo con su tribu de los Amalos se establece en Rávena transformando esta banda guerrera en un pueblo próspero que vivió en paz en Italia, durante los treinta y tres años que duró su reinado. Creemos que el respeto que demostró hacia el pasado del pueblo con-

\footnotetext{
${ }^{4}$ HORACIO. Epodos y Odas. Alianza Editorial, S.A. Madrid 1985. (Libro III, nº 6).
} 
quistado fue otro ejemplo emblemático en la Historia de las civilizaciones y quizás uno de los principales motivos para que pudieran llevarse a cabo estos largos años de paz. Por un lado, conservó la administración imperial, buscando entre los funcionarios sus más brillantes colaboradores: Boecio y Cosiodoro, reconociendo con este gesto la superioridad cultural de Roma. Por otro, muchos fueron sus gestos de respeto hacia el pasado del pueblo conquistado.

«Pregonáronse edictos para precaver los abusos, el abandono y el robo de los mismos ciudadanos, aplicándose, además de un arquitecto expreso, la suma anual de doscientas libras de oro, veinte y cinco mil tejas y el producto de los derechos del puerto Lucrino para el reparo corriente de los muros y edificios públicos. Alcanzó la providencia a las estatuas de metal ó de mármól de hombres y animales... y se nombró un empleado para el restauro de aquellos artefactos, que Teodorico conceptuaba como las galas mas esclarecidas de su reino..1

Teodorico se dejó seducir por la ciudad eterna, a pesar de que cuando visitó Roma se encontraba en un estado semi-ruinoso. Fue tan grande la admiración y el respeto que le invadieron sus monumentos que inmediatamente se dispuso a dictar normas estrictas para su conservación. Al igual que preveía el castigo a los malhechores, en caso de descubrir algún tipo de expoliación de sus materiales, según se recoge en las Variae, de Casiodoro. Este es un hecho sin precedentes en toda la Edad Media.

¿Las múltiples referencias estéticas que podemos encontrar durante estos siglos, deben ser examinadas solamente desde el punto de vista artístico?. Creemos que no. El arte antiguo fue imitado por razones mucho más complejas que la mera valoración estética, tanto durante la Edad Media como en el Renacimiento.

A esta situación hacía referencia Rafael en una carta dirigida al Papa León X:

« Cuantos Pontífices, Santo Padre... han pretendido destruir los templos las estatuas y otras gloriosas construcciones antiguas!. ;Cuanta cal se ha hecho de estatuas y otros ornamentos antiguos!... Toda esta

\footnotetext{
${ }^{5}$ GIBBON, Edward. «Historia de la decadencia y ruina del Imperio romano». Tomo V. Invasiones de los bárbaros y revoluciones de Persia. (Años 455 a 642). Ediciones Turner, S.A. Madrid 1984, pág. 17.
}

"CUADERNOS DE ESTUDIOS GALLEGOS", Tomo XLII, Fascículo 107, Santiago 1995. 
Roma nueva que ahora vemos, a pesar de lo grande que es y de lo hermosa, está totalmente construida con cal procedente de antiguos mármoles. Por consiguiente, Santo Padre, no debería contarse entre los últimos pensamientos de su Santidad interesarse porque lo poco que quede de esta antigua madre de gloria y grandeza itálica no sea extirpado por los malévolos y los ignorantes».

Poco después, Rafael fue nombrado Superintendente de Antigüedades. A pesar del indudable avance que esto supuso, en cuanto a la conservación de las obras heredadas, los problemas siguieron existiendo ya que el valor artístico era un concepto objetivo siempre con la referencia del canon estético establecido por la Grecia clásica. Es precisamente en este momento, cuando se destruyen o se enmascaran gran cantidad de edificaciones medievales, consideradas como manifestaciones culturales de una época oscura. En general, nadie mostraba deseos de conservar el pasado por el propio pasado.

Es en el Renacimiento cuando se produce un avance conceptual importante ya que se reconoce abiertamente el valor histórico de los monumentos considerándolos parte de una larga cadena evolutiva, aunque limitado a la historia anterior del propio pueblo. Como consecuencia, se promulgan las primeras normas de conservación de monumentos (Breve de Paulo III de 28-11-1534).

En el siglo XVIII se sigue avanzando en cuanto al reconocimiento de otros estilos, pero sigue sin dudarse la ejemplaridad del arte clásico. Paralelamente surge un culto a las ruinas, precursor de lo que será el culto a la antigüedad.

\section{REUTILIZACIONES}

No se sabe el momento exacto en que empieza a generalizarse la práctica de la REUTILIZACIÓN de piezas arquitectónicas, escultóricas o pictóricas de épocas pasadas, pero posiblemente se encuentre en la recién creada burguesía promocionada por la dinastía Julio-Claudia.

La estabilidad social y política hizo asumir rápidamente nuevos cánones estéticos. El lujo pasó a ser asumido totalmente por la sociedad surgida de la Pax Augústea. Los edificios de la ciudad se vieron rápidamente enriquecidos con todo tipo de materiales, surgiendo paralelamente las primeras adquisiciones de villas en el campo decoradas dentro del más puro 
estilo helenístico. Para ello, ante la ya escasez de materiales procedentes de las ciudades mediterráneas, se lleva a cabo un desmantelamiento paulatino y sistemático de las viviendas urbanas. Hasta tal punto, que empiezan a surgir especuladores que se dedican a comprar edificios en la ciudad, para reutilizar sus materiales en viviendas construidas en el campo.

Esta práctica debió de extenderse tan pronto, que ya en el año 44 encontramos los primeros intentos de ponerle freno. El aspecto de las ciudades se estaba empobreciendo y con ello se ponía en evidencia el esplendor del régimen político establecido, cuyas manifestaciones externas debían de representar el poderío y la riqueza en sus construcciones urbanísticas.

El senadoconsulto Hosidiano, encontrado entre las ruinas de Herculano, planteaba ya esta situación. Las expoliaciones y el despojo de elementos artísticos en la ciudad, era analizada desde el punto de vista delictivo.

Según el estudio realizado por José Luis Murga en su obra «Protección a la estética en la legislación urbanística del Alto Imperio»:

«... El negocio lucrativo de adquirir por poco dinero los inmuebles venerables para vender sus bellos despojos artísticos, sus mármoles, relieves y columnas se les antojaba al Senado realmente como una auténtica sangría que dejaba vacía a la ciudad de sus elementos más bellos.» ${ }^{6}$

Más que una preocupación estética, lo que seguía primando en la mentalidad de los romanos, era la idea de que la propia ciudad se vería amenazada y con ella lo que representaba: la paz y la felicidad que propugnaban sus gobernantes.

«Esta pequeña intuición — sigue diciendo Murga-que parece traslucirse en la parte introductoria del senadoconsulto viene a ser como una premonición de lo que luego será el elemento primordial en toda la legislación imperial sobre el urbanismo de los siglos IV y V en donde el bien común y los intereses públicos prevalecerán ya claramente incluso frente al posible ius abudenti de los dueños.» ${ }^{7}$

\footnotetext{
${ }^{6}$ MURGA GENER, José Luis. Protección a la estética en la legislación urbanistica del Alto Imperio. Universidad de Valladolid, pág. 19.

${ }^{7}$ Idem, pág. 20.
}

"CUADERNOS DE ESTUdIOS GALLEGOS", Tomo XLII, Fascículo 107, Santiago 1995. 
Todos estos intentos parecían querer evitar lo inevitable, la lenta destrucción de Roma. Pero con el tiempo, ella misma - la primera y gran expoliadora de los bienes artísticos de la mítica Grecia-, hubo de sufrir en sus propios vestigios, un lento y prolongado saqueo. Para mayor tristeza, serán los mismos emperadores romanos los que lo iniciarán.

Constantino fue el primero en dar ejemplo. Al trasladar la capital del Imperio a Constantinopla, inicia una metódica y continuada expoliación, cuyo fin no era otro que embellecer la nueva capital del Imperio. Sus sucesores, no hicieron más que seguir su ejemplo. Esta reutilización de piezas del pasado, le permitió transformar, en un corto período de tiempo, a Constantinopla en una ciudad digna, - por sus monumentos, por su nueva imagen-, de convertirse en una nueva Roma.

Pero entre las causas que decidieron la reutilización de materiales hay que citar la acuciante crisis económica, convirtiéndose en factor determinante a la hora de la utilización de obras de arte construidas en otras épocas.

El uso de materiales procedentes de los monumentos heredados, desde ladrillos a columnas, capiteles o basas, serían aprovechados indiscriminadamente en la construcción monumental cristiana posterior.

¿Es que la Edad Media ignoraba los valores estéticos de los monumentos que estaba destrozando?. Seguro que no. Pero las necesidades económicas imperantes, convirtieron al edifico en un punto de mira, válido única y exclusivamente en función de su utilidad. Las consecuencias no se dejaron esperar: Roma durante la Edad Media se convirtió en una cantera de piedra, de mármol para transformar en cal, de bronce para fundir y utilizar como proyectiles.

\section{NUEVAS FUNCIONES}

Encontramos también en Roma, el mejor ejemplo que se haya dado jamás, a cerca de la reutilización de los edificios antiguos. Del saqueo, sólo sobrevivieron los edificios que por cualquier motivo se les adjudicó una nueva función.

La decisión de trasladar la capital a Constantinopla, había provocado la emigración de la mayoría de los funcionarios y del poder político, con ellos se marchó también el potencial económico. La falta de función provocó el abandono de los edificios, la indiferencia de la gente hacia ellos y su posterior olvido, por el contrario, determinados monumentos fueron conservados gracias a la adjudicación de nuevas funciones.

"CUADERNOS DE ESTUDIOS GALLEGOS", Tomo XLII, Fascículo 107, Santiago 1995. 
La Iglesia necesitaba cada vez más instalaciones debido al número cada vez mayor de sus fieles, por ello fue la primera en hacer la conservación de determinados edificios.

Del mismo modo, se mantuvieron otros que de por sí ya tenían una utilidad práctica por lo que el pueblo siguió frecuentándolos y manteniéndolos.

En el siglo XIX encontramos otro curioso paralelismo más entre el gusto ecléctico romano y el eclecticismo decimonónico, momento en que Viollet le Duc, propone adjudicar nuevas funciones a los edificios medievales, con el fin de conservarlos.

Desde mediados del siglo XIX las referencias a la antigüedad se convierten en un CULTO que no será otra cosa que la maduración definitiva de todos los procesos anteriormente expuestos y que tenían su origen en Roma. las excavaciones que dieron lugar al descubrimiento de Pompeya y Herculano dieron el espaldarazo definitivo. Poco después, Winckelmann aplicaría el método histórico al estudio de la añorada Antigüedad. Surge entonces la investigación histórica y con ella el valor por la antigüedad.

Es también en el siglo XIX cuando se emancipan todos los períodos artísticos, consolidándose a inicios del siglo siguiente momento en el que la obra de arte adquiere un valor propio, subjetivo y variable o kunstwollen - voluntad de arte distinta- Al mismo tiempo, la antigüedad adquiere un valor por sí misma.

El monumento es, desde entonces, un episodio concluido.

La consecuencia inmediata fue: EL NACIMIENTO DE LA CONCIENCIA HISTÓRICA.

A partir de este momento se le confiere a la obra de arte un valor definitivo y concluido, su consecuencia es el NACIMIENTO DE LA RESTAURACIÓN: Considerada, en este momento, como un complejo número de operaciones destinadas, no a actualizar el monumento, ni siquiera a enriquecerlo, sino a conservarlo en base a su valor como testimonio que fue del pasado. 